
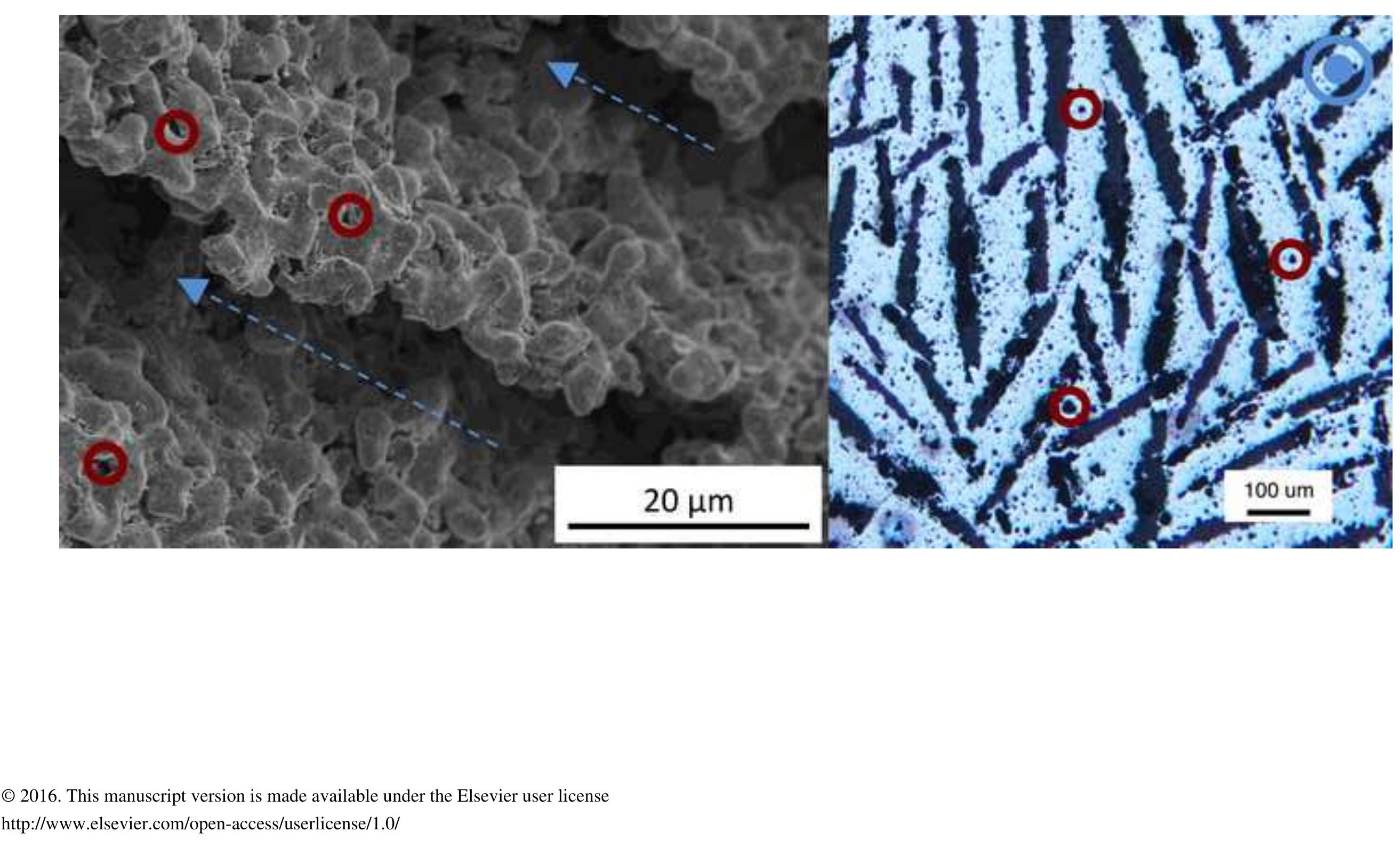


\title{
Iron foams created by directional freeze casting of iron oxide, reduction and sintering
}

Amelia A. Plunk ${ }^{\mathrm{a}}$ and David C. Dunand ${ }^{\mathrm{a}}$

\begin{abstract}
Iron foams with aligned, lamellar channels were created by directionally freeze-casting slurries of water and $\mathrm{Fe}_{2} \mathrm{O}_{3}$ nanopowders, sublimating the ice, and reducing and sintering under hydrogen the powders accumulated in the interdendritic spaces. Foam porosity decreases from 85 to $50 \%$ with $\mathrm{Fe}_{2} \mathrm{O}_{3}$ slurry fractions increasing from 14 to $23 \mathrm{vol}$. \%. For foams created from 18.5 vol. $\% \mathrm{Fe}_{2} \mathrm{O}_{3}$ slurries, with increasing sintering temperature from 900 to $1100^{\circ} \mathrm{C}$, a decrease in porosity from 71 to $61 \%$ and an increase in unidirectional compression strength from 8 to $20 \mathrm{MPa}$ are observed.
\end{abstract}

\section{Keywords}

freeze-casting; iron; iron oxide; metallic foam; Fe2O3

\section{Introduction}

Directional freeze-casting is a bottom-up templating technique that has seen extensive use over the past decade to create ceramic foams with aligned, elongated channels tens to hundreds of micrometers in width, and millimeters to centimeters in length [1]-[3]. Micropores within channel walls can occur due to incomplete sintering, increasing surface area of the foams. Directional freeze-casting is based on the following steps: (i) slurry is created with fine ceramic powders in suspension in liquid; (ii) suspension is frozen directionally; ice dendrites grow along the temperature gradient and push the suspended powder in the interdendritic space; (iii) ice is sublimated, leaving aligned, lamellar channels replicating the ice dendrites, surrounded by ceramic powder walls; (iv) powder walls are sintered into the dense walls of a strong ceramic foam. For metallic foams, the same method can be used with metallic powders as demonstrated for $\mathrm{Ti}$ [4], [5], or with oxide powders which are reduced before or during sintering, as demonstrated recently for $\mathrm{Cu}$ [6], [7], $\mathrm{Ni}$ [8], and $\mathrm{W}$ [9]. This latter method overcomes difficulties associated with suspending fine metallic powders in water, i.e., powder rapid settling in the suspension and premature engulfment by ice dendrites due to higher densities of metals as compared to oxides, and oxidation of submicron powders required to prevent engulfment. Recent work [10] has shown the ability to freeze-cast nanometric hematite $\mathrm{Fe}_{2} \mathrm{O}_{3}$ powders in liquid camphene to create hematite foams, displaying cylindrical pores with high aspect ratio; hydrogen reduction to iron was also demonstrated. In the present work, we demonstrate for the first time the combination of directional freeze-casting of nanometric $\mathrm{Fe}_{2} \mathrm{O}_{3}$ powders in water, creating aligned, lamellar ice dendrites with nanopowders rejected 
to the interdendritic space, and reduction and sintering in a hydrogen atmosphere to create iron foams with aligned, lamellar channels and micropores within channel walls. Parameters controlling the freezecasting, reduction and sintering process are explored and discussed. These directional iron foams could be used for structural applications [11], for resorbable biomedical implants [12] and for redox cycling in iron-air batteries. In the latter application, freeze-cast iron foams are expected to show a unique combination of permeability, high surface area and resistance to sintering, superior to current iron powder beds [13]-[16].

\section{Experimental}

Slurries were prepared for freeze-casting by dissolving 4.5 vol. \% poly(ethylene glycol) binder (PEG, Sigma-Aldrich, avg. $\mathrm{M}_{\mathrm{n}}: 400$ ) into deionized water together with 2 vol. \% of a commercial dispersant. Mixture was stirred for 30 minutes. Subsequently, $14,18.5$ or 23 vol. \% $\mathrm{Fe}_{2} \mathrm{O}_{3}$ nanopowders $(40-60 \mathrm{~nm}$, from US Nano LLC) were added; slurry was stirred for 30 minutes more. Slurries were poured into cylindrical Teflon molds, sealed on the bottom by thin copper foil. The filled mold was placed on a copper rod cooled to $-17^{\circ} \mathrm{C}$. The sides and top of the mold were insulated using polystyrene foam to prioritize the vertical temperature gradient. Slurries were left to freeze on the copper rod for $\sim 90$ minutes until solidified. Frozen samples were removed from the mold and transferred to a freeze dryer (Labconco Corp.). Here, samples were held at 0.133 mbar and a collector temperature of $-40^{\circ} \mathrm{C}$ for 24 hours for ice sublimation.

After sublimation, green bodies were subjected to a three-step heat-treatment in a tube furnace under pure flowing $\mathrm{H}_{2}$ : (1) $300^{\circ} \mathrm{C}, 1$ hour: dispersant and binder burnout, (2) $600^{\circ} \mathrm{C}, 4 \mathrm{~h}$ : chemical reduction, (3) 900,1000 or $1100^{\circ} \mathrm{C}, 3 \mathrm{~h}$ : sintering. Full reduction from $\mathrm{Fe}_{2} \mathrm{O}_{3}$ to $\mathrm{Fe}$ was confirmed through weight loss comparison to theoretical values and through X-ray diffraction (XRD). Longitudinal and radial crosssections were cut and examined using scanning electron microscopy (SEM), and were also impregnated with resin and polished for examination using optical microscopy.

Uniaxial compression tests were conducted using a servo-hydraulic mechanical testing system on iron foams cut into $5 \times 5 \times 10 \mathrm{~mm}^{3}$ rectangular prisms using a low-speed diamond saw. The samples were loaded parallel to the alignment of channels.

\section{Results and Discussion}

Figures 1a-b show optical micrographs of polished cross-sections of a representative Fe foam in the planes parallel and perpendicular to the temperature gradient. Foams display colonies of parallel walls surrounding aligned, lamellar channels. These lamellar channels extend from the base to the top of the sample, as illustrated in Figure 1a. A similar channel and wall structure was reported in $\mathrm{Cu}, \mathrm{Ni}$ and $\mathrm{W}$ foams created by through similar pathways [6]-[9].

Two processing parameters were studied: (i) sintering temperature; (ii) volume fraction of $\mathrm{Fe}_{2} \mathrm{O}_{3}$ in slurry. As shown in Figure 2a, porosity of the sintered foams decreases with increasing sintering temperature (from $\sim 70 \%$ at $900^{\circ} \mathrm{C}$ to $\sim 60 \%$ porosity at $1100^{\circ} \mathrm{C}$ ) for a constant $\mathrm{Fe}_{2} \mathrm{O}_{3}$ slurry fraction of $18.5 \mathrm{vol} \%$; this decrease in porosity is also shown in channel thickness measurements, which decrease from $\sim 46 \mu \mathrm{m}$ at $900^{\circ} \mathrm{C}$ to $\sim 40 \mu \mathrm{m}$ at $1100^{\circ} \mathrm{C}$, while wall thickness is $\sim 36 \mu \mathrm{m}$ for all three samples. Figure $2 \mathrm{~b}$ shows that for a constant sintering temperature of $1100^{\circ} \mathrm{C}$, varying the $\mathrm{Fe}_{2} \mathrm{O}_{3}$ slurry fraction from 14 to 23 vol. \% decreases foam porosity from $\sim 85$ to $\sim 50 \%$ porosity, a result consistent with the decreasing 

study on directional freeze-cast tungsten foams shows similar trends [9].

In Figure 3(a-c), SEM and optical micrographs illustrate the three-dimensional microstructure of the Fe foams, particularly the lamellar channels and Fe walls. In Figure 3(b-c), the presence of micropores at wall surfaces and within the walls is confirmed, which increases the free surfaces and may mitigate internal stresses associated with volume changes during cyclical redox and the resulting tendency for sintering and/or pulverization.

Compressive engineering stress-strain curves were collected using a $50 \mathrm{kN}$ load cell and are shown in Figure 4 for foams freeze-cast with $18.5 \% \mathrm{Fe}_{2} \mathrm{O}_{3}$ slurry fraction and sintered at 900,1000 and $1100^{\circ} \mathrm{C}$. All samples show behaviors similar to typical honeycombs in compression, with a three-section stress-strain curve: (i) elastic region; (ii) plastic deformation and energy absorption; (iii) foam densification. The present freeze-cast foams exhibit a sharp drop in stress after peak strength: elasto-plastic buckling is probably active in the highly aligned lamellar channel walls.

Figure 4 shows peak strength increases from 8 to $15 \mathrm{MPa}$ to $20 \mathrm{MPa}$ for foams sintered at 900, 1000 and $1100^{\circ} \mathrm{C}$, with porosities of $71 \%, 86 \%$ and $61 \%$ respectively (Figure $2(\mathrm{a})$ ). These preliminary results fit within the Gibson-Ashby model for peak strength [17], but as these foams have a more complex pore structure than standard honeycomb, a more descriptive model must be developed to describe their mechanical behavior.

Stiffness measurements were performed on each sample by repeatedly loading and unloading, and measuring the slopes of unload curves. Error is large on these measurements, but the trend is towards stiffer foams at higher sintering temperatures, consistent with denser, stronger channel walls. Stiffnesses measured are $1.3,1.6$ and 3.1 GPa with sintering temperature increasing from 900 to 1000 to $1100^{\circ} \mathrm{C}$, respectively.

\section{Conclusion}

We present here a demonstration of directional freeze-casting, reduction and sintering of aqueous $\mathrm{Fe}_{2} \mathrm{O}_{3}$ slurries to create metallic $\mathrm{Fe}$ foams with aligned, lamellar pores. Control over the porosity (ranging from $\sim 50$ to $85 \%$ ) and strength is demonstrated through adjusting sintering temperature (from 900 to $1100^{\circ} \mathrm{C}$ ) and $\mathrm{Fe}_{2} \mathrm{O}_{3}$ fraction in the slurry (from 14 to 23 vol. \%). Mechanical compression data show that an increase in foam strength is associated with increases in sintering temperature, with a maximum strength of $\sim 20 \mathrm{MPa}$ for a foam with $71 \%$ porosity, created from a 18.5 vol $\% \mathrm{Fe}_{2} \mathrm{O}_{3}$ slurry and sintered at $1100^{\circ} \mathrm{C}$.

\section{Acknowledgments}

AP was supported by the National Science Foundation through a Graduate Research Fellowship under grant no. DGE-1324585. The Northwestern Universities Optical Microscopy and Metallography Lab, Electron Probe Instrumentation Center, and Central Laboratory for Materials Mechanical Properties are acknowledged. The authors acknowledge Dr. Ranier Sepúlveda for experimental assistance.

\section{References}


[1] S. Deville, Adv. Eng. Mater., vol. 10, no. 3, pp. 155-169, 2008.

[2] S. Deville, et al., Sci. Technolo. Adv. Mater., vol. 16, no. 4, p. 043501, Aug. 2015.

[3] H Bai, et al., Sci Adv., vol. 1, no. 11, p. e1500849, 2015.

[4] D. C. Dunand, Adv. Eng. Mater., vol. 59, no. 1, pp. 369-376, 2004.

[5] J. C. Li, D. C. Dunand, Acta Mater., vol 59, no. 1, pp. 146-158, Jan 2011.

[6] J. H. Um, et al., Sci. Rep., vol. 6, no. 18626, 2016.

[7] A. I. C. Ramos, D. C. Dunand, Metals (Basel)., col. 2, no. 4, pp. 265-273, Aug. 2012.

[8] H. Jo, et al. Metall. Mater. Trans. E, vol. 3, no. 1, pp. 46-54, 2016.

[9] A. Röthlisberger, S. Häberli, R. Spolenak, and D. Dunand, J. Mater. Res., 2016.

[10] R. Sepúlveda, A. A. Plunk, D. C. Dunand., Mater. Lett., vol. 142, pp. 56-59, Mar. 2015.

[11] T. Murakami, et al., Mater. Trans., vol. 48, no. 11, pp. 2937-2944, Oct. 2007.

[12] J. Čapek, et al., Mater. Des., vol. 83, pp. 468-482, Oct. 2015.

[13] X. Zhao, et al., RSC Adv., vol. 4, no. 43, p.22621, 2014.

[14] N. Xu, et al., Energy Environ. Sci., vol. 4, no. 12, pp. 4942-4946, Nov. 2011

[15] A. Z. Weber, et al., J. Appl. Electrochem., vol. 41, no. 10, pp. 1137-1164, Sep. 2011.

[16] C. Ponce de León, et al., Power Sources, vol. 160, no. 1, pp. 716-732, Sep. 2006.

[17] L. J. Gibson, F. M. Ashby, Cellular Solids: Structure \& Properties. Cambridge University Press, p.532, (1999).

\section{List of Figures}

Figure 1 - Optical micrograph of iron foam reduced and sintered from 20 vol. \% Fe203 slurry. Cross-sections are (a) longitudinal, showing short-range lamellar channel structure consistent with conventional unidirectional freeze-casting [3] separated by Fe walls, and (b) radial, showing lamellar channels parallel to each other within colonies of consistent size.

Figure 2 - Effect on foam porosity of (a) sintering temperature at constant Fe203 slurry fraction of 18.5 vol.\%, and (b) Fe2O3 slurry fraction at constant sintering temperature of $1100 \mathrm{oC}$.

Figure 3 - Arrows indicate freezing direction and red circles show micropores within channel walls. (a) SEM micrograph showing wall microstructure of Fe foam reduced and sintered from a 20 vol. \% Fe203 slurry. (b) High-magnification SEM micrograph of channel walls with extensive surface porosity. (c) Optical micrograph of radial cross-section.

Figure 4 - Compressive stress-strain curves for foams freeze-cast from 18.5 vol.\% Fe203 slurry, sintered at various temperatures and with various porosities. Inset: Yield strength of foams as a 
function of sintering temperature. There are no error bars because we were only able to complete one compression test for each sintering temperature. 


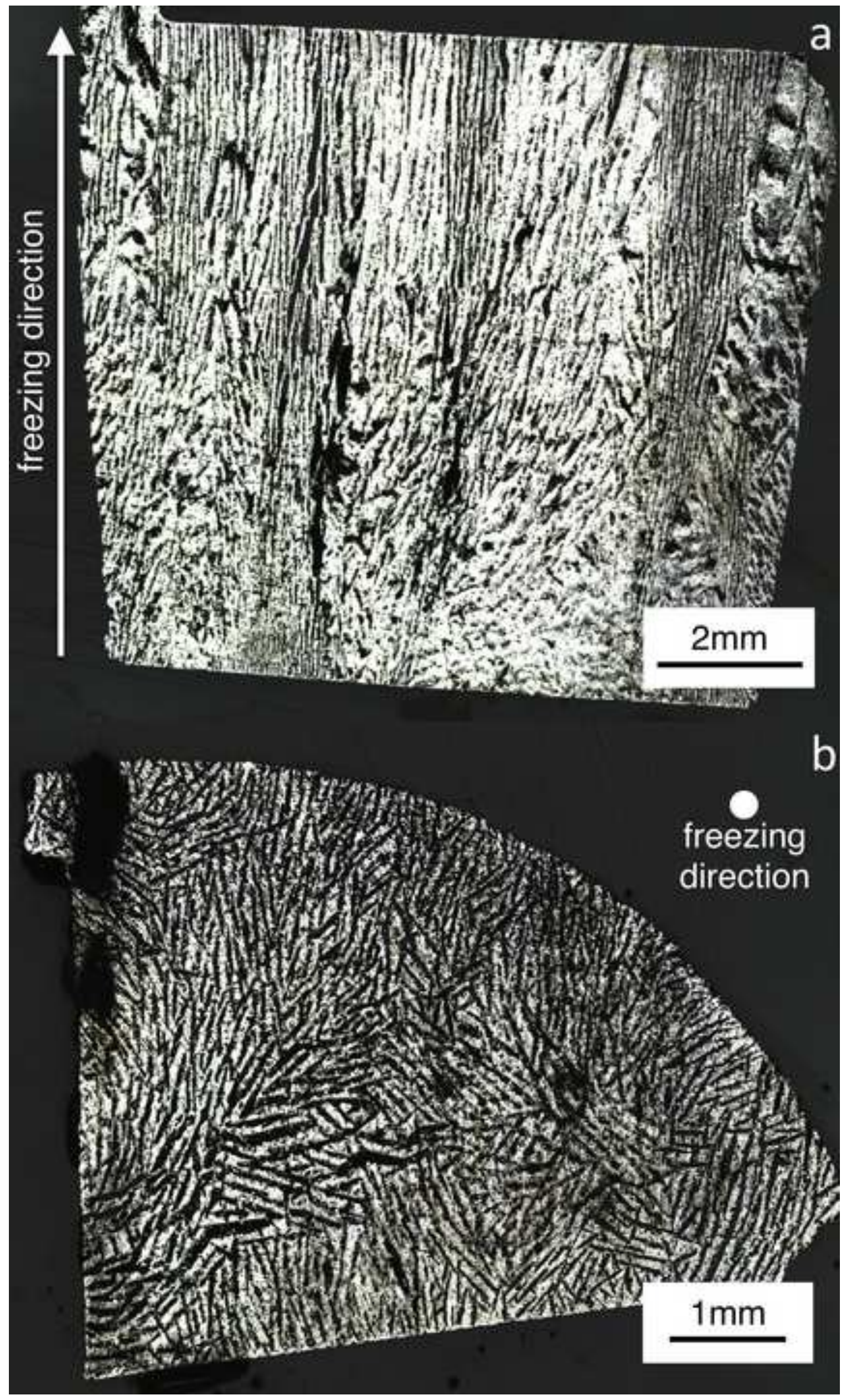

tit

(1)

- 40

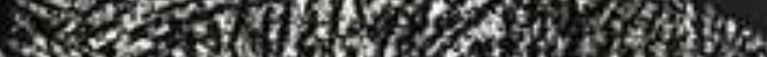

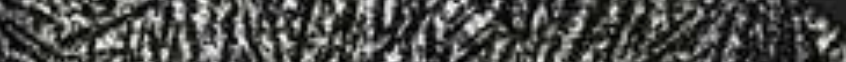

Soth

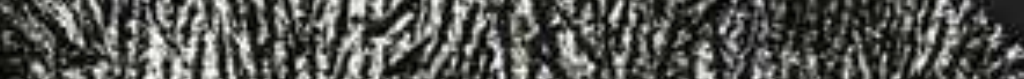

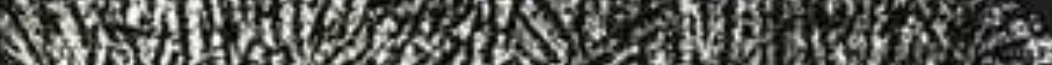

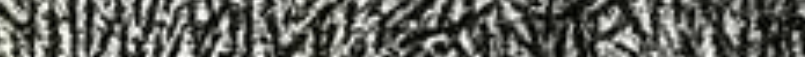

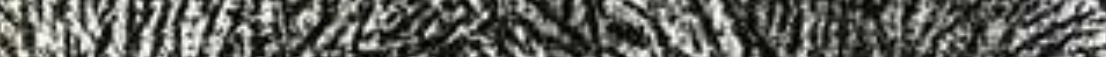



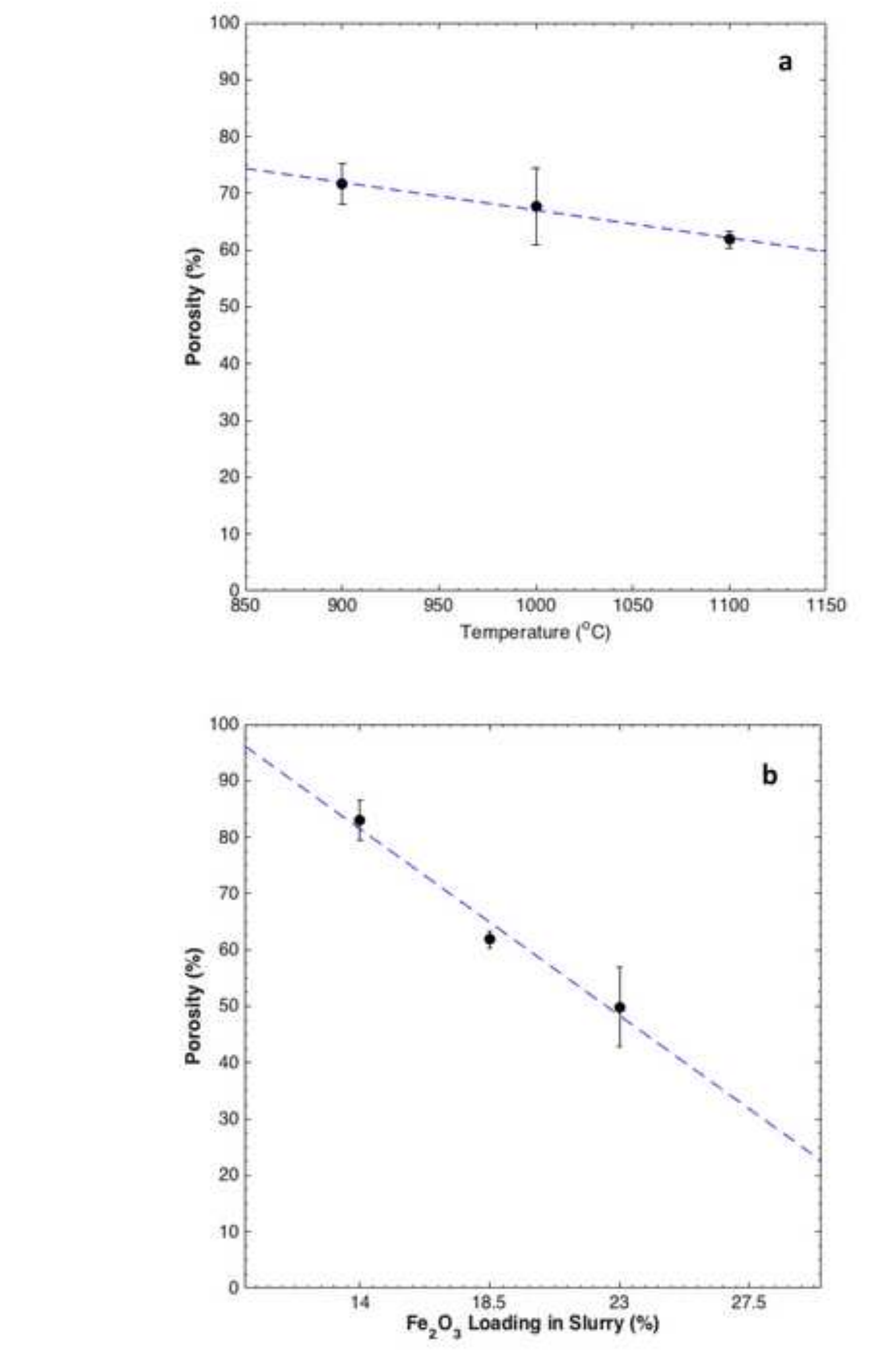

Figure 2

2

\section{Figure 2}
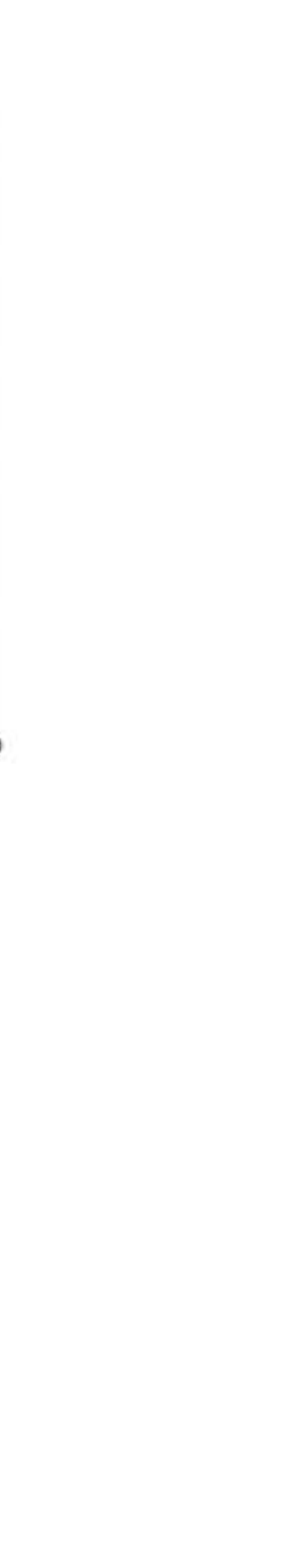


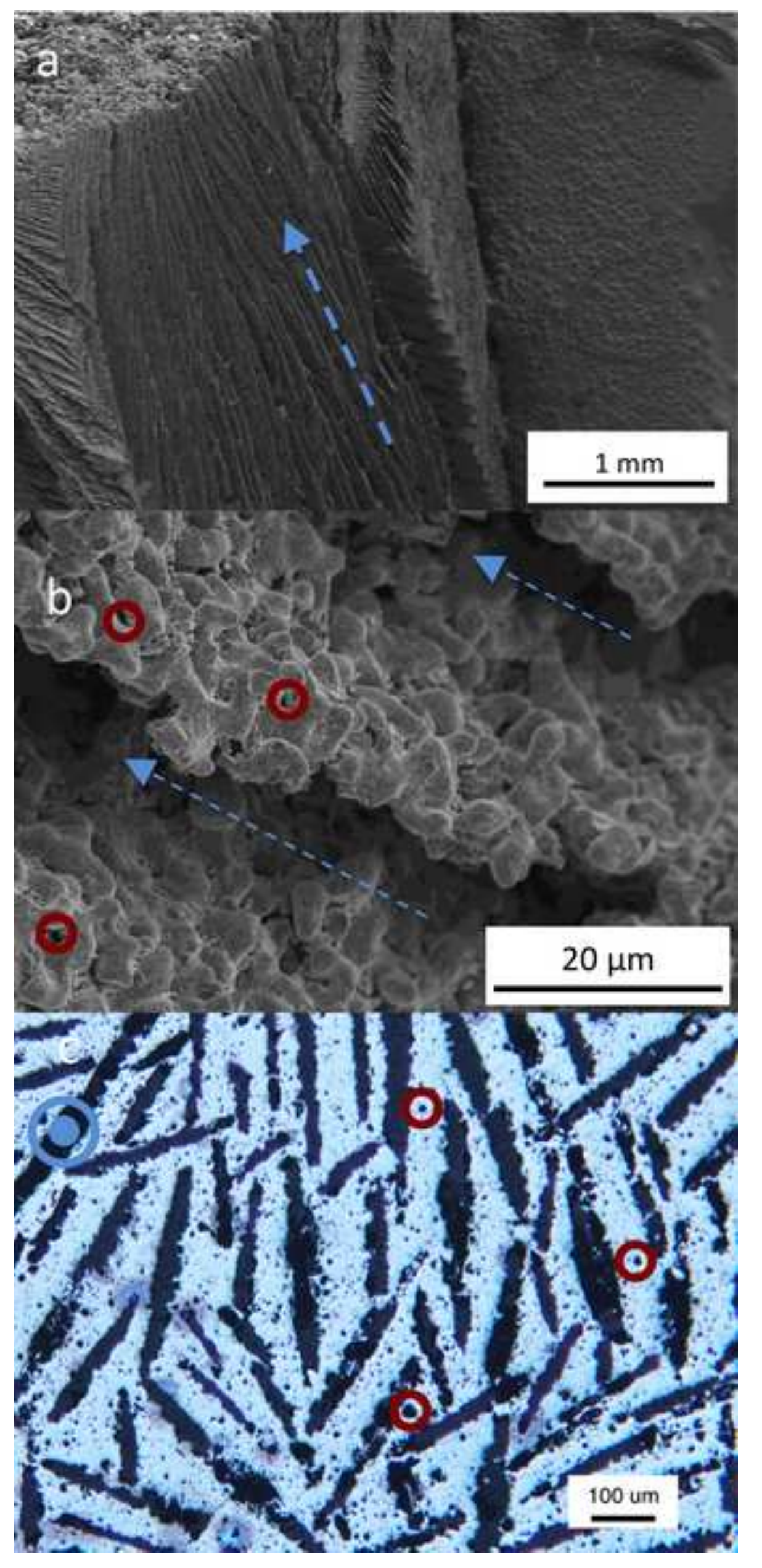

Figure

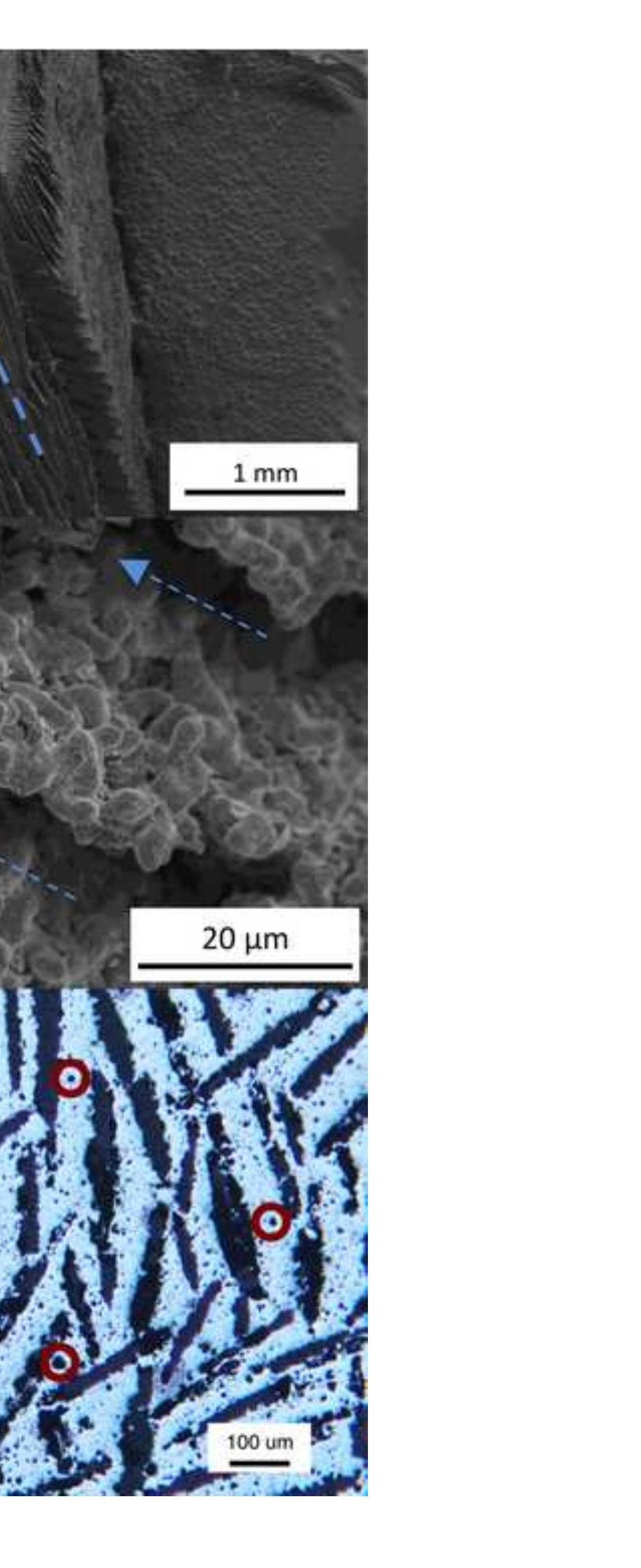




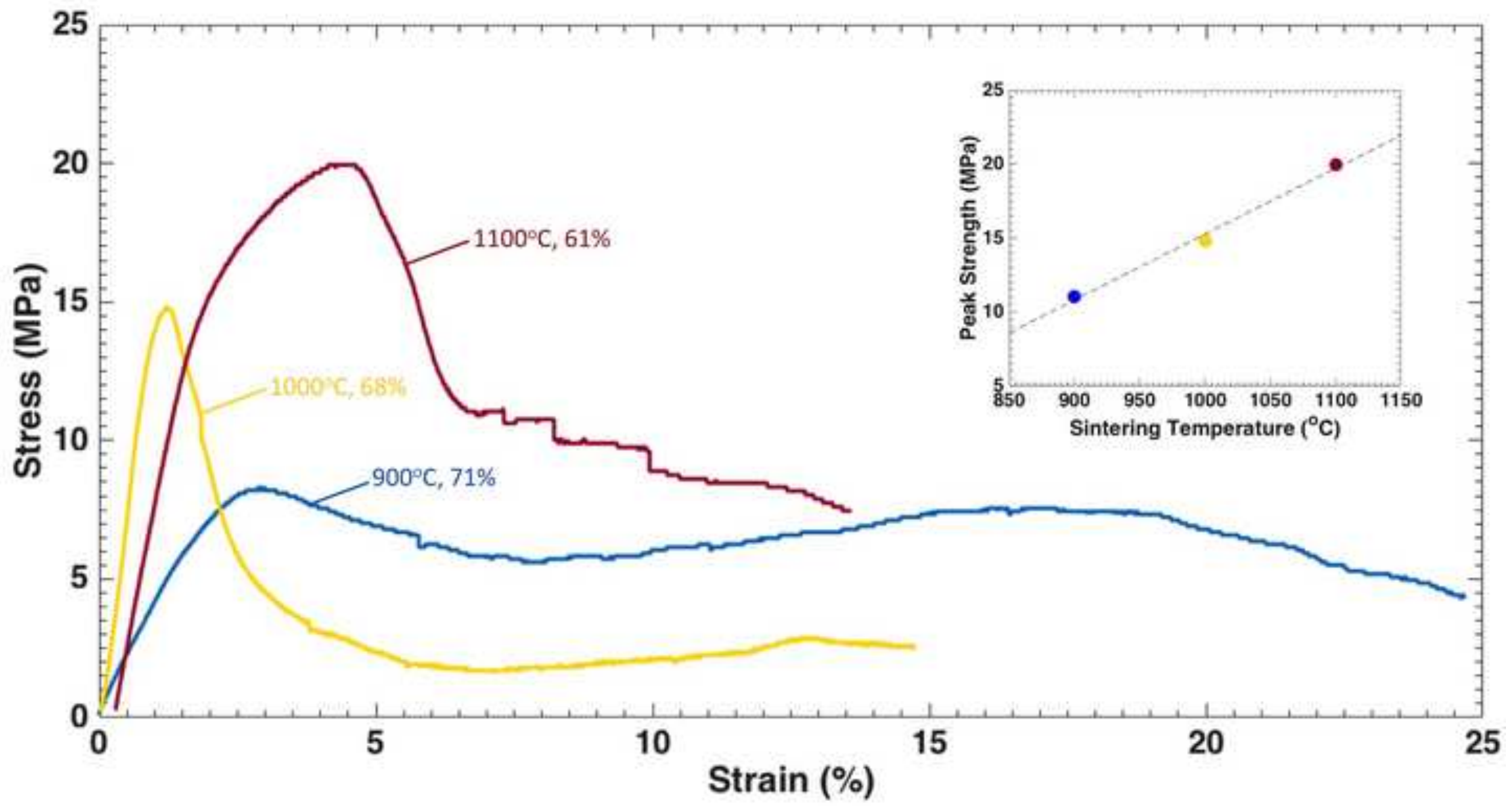

